20

\title{
Спектральный анализ органических компонентов деминерализованных костных биоимплантатов*
}

\author{
(C) П.Е. Тимченко ${ }^{1}$, Е.В. Тимченко ${ }^{1}$, Л.Т. Волова ${ }^{2}$, О.О. Фролов ${ }^{1}$ \\ ${ }^{1}$ Самарский национальный исследовательский университет имени академика С.П. Королева (Самарский университет), \\ кафедра лазерных и биотехнических систем, \\ 443086 Самара, Россия \\ 2 „Самарский государственный медицинский университет“ \\ Министерства здравоохранения Российской Федерации, \\ Институт экспериментальной медицины и биотехнологий (ИЭМБ), \\ 443079 Самара, Россия \\ e-mail: ssau@ssau.ru, volovalt@yandex.ru.
}

Поступила в редакцию 08.01.2019 г.

В окончательной редакции 19.02.2019 г.

Принята к публикации 23.01.2019 г.

Представлены результаты расширенного спектрального анализа донорских костных имплантатов человека с помощью метода спектроскопии комбинационного рассеяния (КР). Использованы математические методы улучшения разрешения спектральных контуров и хемометрический анализ РСА для оценки органических компонентов имплантатов. Результаты сопоставлены с протеомным анализом, осуществляемым методом масс-спектрометрии. Основные различия между кадаверными и интраоперационными биоимплантатами проявляются на линиях КР 1450, $1735 \mathrm{~cm}^{-1}$ (липиды и жирные кислоты), 917 и $937 \mathrm{~cm}^{-1}$ (гликоген), 814 и $894 \mathrm{~cm}^{-1}$ (ДНК) и 1238, $1560 \mathrm{~cm}^{-1}$ (амид II, амид III). Показано, что спектроскопия КР может быть использована для оценки относительной концентрации компонентов, входящих в состав ДНК, РНК, коллагенов, протеинов, экстраклеточного матрикса и костной ткани.

DOI: 10.21883/OS.2019.06.47780.60-19

\section{Введение}

На данный момент актуальной задачей импланталогии является оценка качества обработки биоимплантов, производимых для восстановления дефектов костной ткани и остеогенеза.

Биоматериалы играют решающую роль в тканевой инженерии, поскольку они поддерживают форму и структуру развивающихся тканей, обеспечивают механическую стабильность и возможность транспортировки необходимых веществ. Поэтому качество используемого биоматериала может оказать сильное влияние на вновь сформированные ткани и зависит от метода приготовления имплантата [1].

Костный имплантат должен служить основой для поддержки новых кровеносных сосудов и мягких тканей, а также соответствовать заменяемому участку костной ткани по химическому составу, в частности по концентрации примесей. Использование остеообразующих донорских имплантатов ограничено риском инфицирования и иммунологического отторжения трансплантата, что увеличивает сроки восстановления, поскольку в процессе создания имплантатов происходит загрязнение

\footnotetext{
* The 22nd Annual Conference Saratov Fall Meeting 2018 (SFM'18): VI International Symposium „Optics and Biophotonics“ and XXII International School for Junior Scientists and Students on Optics, Laser Physics \& Biophotonics, September 24-29, 2018, Saratov, Russia. https://www.sgu.ru/structure/fiz/saratov-fall-meeting/previousconferences/saratov-fall-meeting-2018
}

их поверхности [2]. Очистка поверхности имплантата может проводиться химическими способами, что приводит к удалению клеток донора и разрушению нуклеиновых кислот. Однако при этом может происходить уменьшение содержание ключевых компонентов биоматрикса: денатурация белков и деформация коллагеновой матрицы, что приводит к нарушению биологических и механических свойств костной ткани [3].

Изучение костных белков и их модификаций стало актуальной задачей для лучшего понимания и выявления болезней костей. Однако, поскольку кость минерализована, анализ содержания белка в кости является более сложным, чем анализ белков в других неминерализованных тканях [4].

Приживляемость биоимплантатов зависит от удаления клеточных белков и нуклеидов - основного фактора антигенности, а также от их качества и технологии производства, направленной на сохранение необходимых биологических веществ, участвующих в регенеративном процессе, таких как гидроксиапатит, коллаген, гликозаминогликаны, остеопонтин, остеомодулин, остеоглицин и др. [5,6]. Поэтому необходим постоянный контроль качества изготовляемых имплантатов с оценкой органической составляющей. На современном уровне развития науки и техники для решения этой задачи могут быть применены оптические методы исследования, поскольку они могут использоваться как скрининговые, быстро выполняемые, малозатратные методы, без разрушения 
представленных образцов в отличие от морфологических, морфометрических, биохимических исследований $[7,8]$. Метод спектроскопии комбинационного рассеяния (КР) [9-11] находит широкое применение для контроля качества материалов тканевой инженерии.

Так, например, в работе [12] использован метод спектроскопии КР для исследования 26 белков разной структуры, функции и свойств. Выделенные белки были разделены согласно структурной классификации белков на четыре класса по их вторичной структуре: $\alpha$-спиральный $(\alpha), \beta$-sheet $(\beta)$, смешанные структуры $(\alpha / \beta, \alpha+\beta, s)$ и другие. Установлено, что спектроскопия КР может быть использована для неинвазивного и неразрушающего анализа состава биоимплантатов в процессе их обработки, в частности очень полезна для идентификации белков и анализа их вторичных структур.

В то же время биоимплантаты представляют собой многокомпонентный биоматрикс, включающий в свой состав экстраклеточный матрикс, гидроксиапатит, коллагеновые структуры, клеточные и белковые компоненты, что в свою очередь делает спектральный контур без специальной математической обработки менее информативным. Поэтому необходимо применять деконволюцию спектров и хемометрический анализ методом главных компонент (РСА) для реализации расширенного компонентного качественного анализа спектров КР [13].

Среди биологических методов анализа широкое применение получил протеомный анализ [14]. Протеом представляет собой весь набор белков, которые продуцируются, модифицируются организмом или системой. Это зависит от множества факторов, которым подвергается организм. Протеомный анализ направлен на одновременное изучение многих индивидуальных белков и позволяет получить качественное и количественное описание белков, входящих в состав биоимплантатов, что обеспечивает диагностику и мониторинг их качества.

Цель работы: введение новых коэффициентов для оценки органических компонентов деминерализованных костных имплантатов, полученных из кадаверного (трупного) и интраоперационного материалов, методами спектроскопии комбинационного рассеяния и протеомного анализа, что позволит оптимизировать процесс изготовления биоимплантатов.

\section{Материалы и методы исследований}

В качестве объектов исследования были использованы 36 деминерализованных образцов биоимплантов губчатой кости в форме куба размерами $5 \times 5 \times 5 \mathrm{~mm}$, изготовленные по технологии „Лиопласт“ ()(ТУ-9398-00101963143-2004).

В процессе производства костных биоимплантов на первом этапе проводили их низкочастотную ультразвуковую обработку $(24-40 \mathrm{kHz}$ в течение $2-3 \mathrm{~min})$, в ре-

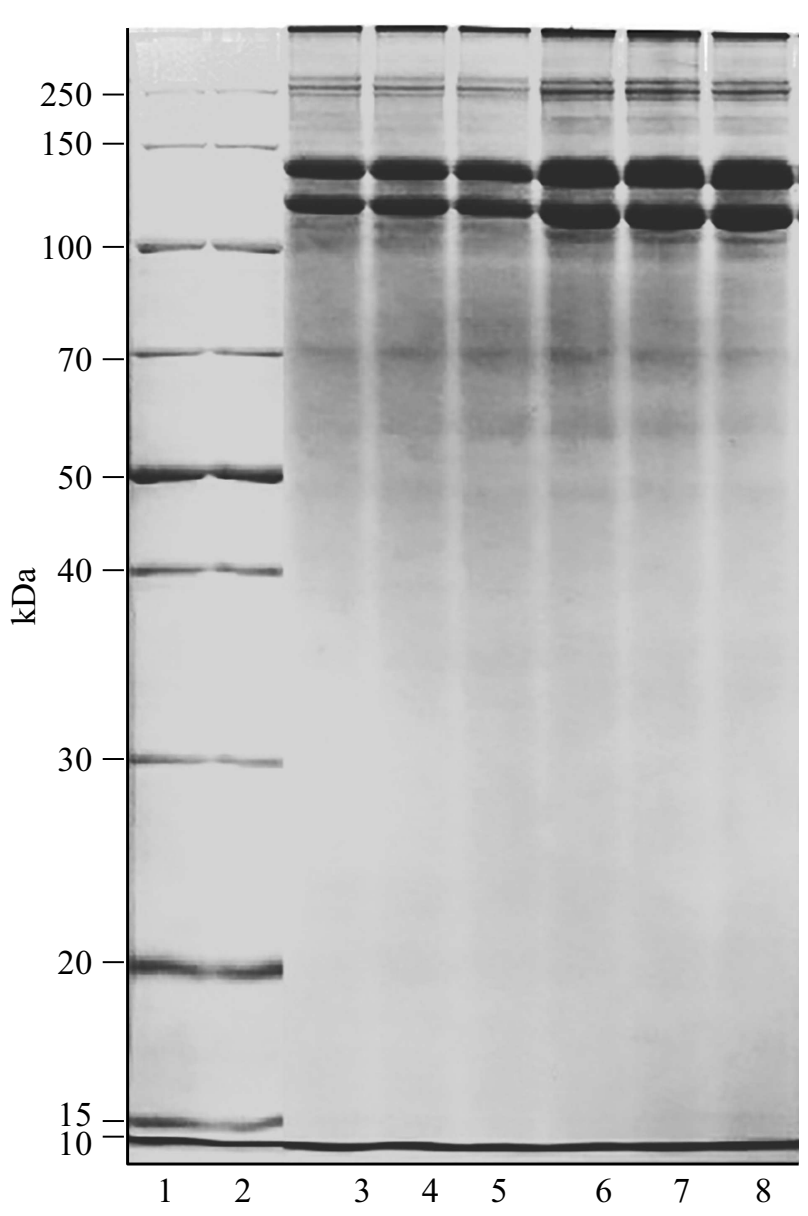

Рис. 1. Электрофореграмма белков, выделенных из деминерализованной костной ткани (препаративный электрофорез): 1,2 - стандарты молекулярной массы; 3-5 - кадаверный материал; 6-8 - материал, взятый в ходе операции (интраоперационный).

зультате которой образцы обезжиривались, происходило удаление всех элементов костного мозга из межбалочных пространств кости. Для получения деминерализованных образцов костную ткань помещали в раствор соляной кислоты слабой концентрации, процент которой зависел от локализации вырезки костного биоматериала и возрастных критериев донора. На следующем этапе выполняли лиофилизацию костей, которая заключалась в сублимационной сушке образцов. Герметично упакованный лиофилизированный материал на заключительном этапе стерилизовали радиационным методом.

Все образцы разделены на две группы по способу получения: аллогенные (кадаверные) и интраоперационно резецируемые. Измерения производились с каждой из шести сторон образца в различных точках и усреднялись.

Контроль качественного состава и относительной концентрации компонентов костных биоимплантатов проводился с помощью экспериментального стенда, включающего в себя рамановский зонд RPB-785, совмещен- 
ный с лазерным модулем LuxxMaster LML-785.0RB-04 (мощность до $500 \mathrm{~mW}$, длина волны $784.7 \pm 0.05 \mathrm{~nm}$ ), и высокоразрешающий спектрометр Shamrock sr-303i, обеспечивающий спектральное разрешение $0.15 \mathrm{~nm}$, со встроенной охлаждаемой камерой DV420A-OE [7,8].

Качественный анализ белков проведен на хроматографе Dionex Ultimate 3000 с использованием колонки AcclaimPepMap C18, $2 \mu \mathrm{m}, 100 \AA, 75 \mu \mathrm{m} \times 15 \mathrm{~cm}$ (Thermo Scientific). В качестве детектора использован масс-спектрометр maXis Impact (Bruker, Германия), оснащенный источником ионов CaptiveSpray. Для получения масс-листов масс-спектры обрабатывали в программе DataAnalysis 4.1 с использованием предустановленного скрипта для анализа продолжительных хроматограмм. По масс-листам идентифицировали белки с помощью программы Mascot 2.4.0. Представленность белков в образце оценивали в программе MultiQuant 3.0.2 по площади пиков MRM-переходов.

\section{Результаты исследований}

\section{Масс-спектрометрия органических компонентов имплантатов}

Результаты протеомного анализа для деминерализованных образцов костной ткани представлены на рис. 1 . Список органических компонентов, идентифицированных при анализе деминерализованной спонгиозы, приведен в табл. 1.

Видно, что наиболее интенсивными являются линии, соответствующие коллагену, фибронектину, тенасцину, жирным кислотам и матриксному Gla-протеину. Концентрация остальных органических компонентов в исследуемых образцах незначительна.

Матриксный gla-протеин $(12.353 \mathrm{kDa})$ ассоциирует с органической матрицей кости и хряща и действует как ингибитор образования костей. Внеклеточный матричный белок тенасцин $(240.853 \mathrm{kDa})$ участвует в управлении мигрирующими нейронами, а также аксонами во время развития, синаптической пластичности, а также регенерации нейронов.

Фибронектины $(262.625 \mathrm{kDa})$ связывают поверхности клеток и различные соединения, включая коллаген, фибрин, гепарин, ДНК и актин. Фибронектины участвуют в клеточной адгезии, подвижности клеток, опсонизации, заживлении ран и поддержании формы клеток. Этот белок участвует в прессовании остеобластов посредством процесса сборки клеток, опосредованного клетками фибронектина, который необходим для остеобластной минерализации. Участвует в регуляции осаждения коллагена І типа остеобластами.

Коллаген действует как клеточный связывающий белок и осуществляет адгезионную функцию путем интеграции пучков коллагена и является основным компонентом экстраклеточного матрикса. Для интраоперационных образцов характерна большая концентрация коллагенов, фибронектина и тенасцина, чем для кадаверных.

\section{Расширенный анализ биоимплантатов методом спектроскопии KP}

Спектры КР представлены для области $300-2200 \mathrm{~cm}^{-1}$. Обработка спектров осуществлялась в программной среде Wolfram Mathematica 10 и заключалась в полиномной аппроксимации при помощи итерационного алгоритма [15] (полином 8-й степени) флуоресцентной составляющей спектра, ее вычитании и получении математически обработанного спектра КР с последующим сглаживанием шумов медианным фильтром по трем точкам. Погрешность введенных коэффициентов не превышала 4\% [11].

Для повышения информативности спектров было проведено моделирование спектрального контура в программной среде MagicPlotPro 2.7.2 путем разложения спектра на линии, описываемые функцией Гаусса [16]. При моделировании спектрального контура у линий, используемых как шаблон, фиксировалось положение и ширина линии. При моделировании подбиралась лишь интенсивность линии. Это позволяло добиться высокой стабильности результатов при моделировании контура. Дальнейший хемометрический анализ с помощью метода главных компонент (РСА) реализован в программной среде The Unscrambler X. Анализ спектров КР представлен в табл. 2.

Для анализа линий КР и получения более детальной информации проведено разделение спектральных линий. С помощью метода подбора спектрального контура и деконволюции функции Гаусса в программной среде MagicPlotPro 2.7.2 был проведен нелинейный регрессионный анализ спектров КР, состоящий в их разложении на спектральные линии (рис. 2). В качестве пробной использовалась функция Гаусса [16]. Среднее значение коэффициента детерминации результирующего спектра от исходного в области 750-2050 $\mathrm{cm}^{-1}$ составляет $R^{2}=0.99$.

Коллаген, гликозаминогликаны, протеогликаны, тирозин, пролин и фенилаланин являются основными компонентами экстраклеточного матрикса. Качество имплантатов определяется его сохранностью и полнотой удаления клеточных компонентов донора (ДНК, РНК) [7,8].

Для относительной количественной оценки компонентного состава поверхности биоимплантов на основе костной ткани нами были введены относительные коэффициенты. Относительно постоянной линией в исследуемых образцах являлась линия амид I [11], соответствующая рамановскому сдвигу частоты $1660 \mathrm{~cm}^{-1}$, поэтому амплитуда этой разделенной линии была использована в качестве знаменателя $\left(I_{1660}\right)$ во введенных коэффициен$\operatorname{Tax}(k)$ :

$$
k_{i}=\frac{I_{i}}{I_{1660}}
$$

где $I_{i}$ - значения интенсивности на спектральных линиях анализируемых компонентов. 
Таблица 1. Список органических компонентов, идентифицированных при анализе

\begin{tabular}{l|c|c}
\hline Белки (полипептидные цепи) & Локализация & Масса, $\mathrm{kDa}$ \\
\hline Matrix Gla protein & Кость & 12.353 \\
Secreted phosphoprotein 24 & Кость & 24.338 \\
Mimecan & Кость & 33.922 \\
SPARC (Osteonectin) & Кость & 34.632 \\
Bone sialoprotein 2 & Кость & 35.148 \\
Osteopontin & Кость & 35.423 \\
Lumican & ЕСМ & 38.429 \\
Alpha-2-HS-glycoprotein & Плазма & 39.325 \\
Decorin & ЕСМ & 39.747 \\
Chondroadherin & Матриксный протеин хряща & 40.476 \\
Biglycan & ЕСМ & 41.654 \\
Fibromodulin & ЕСМ & 43.179 \\
Prolargin & ЕСМ & 43.810 \\
Osteomodulin & Кость & 49.492 \\
Long-chain-fatty-acid-CoA ligase 1 & Пероксисомы 1745 & 77.943 \\
Collagen alpha chain & ЕСМ & $108-168$ \\
Tenascin & ЕСМ & 240.853 \\
Fibronectin & Плазма, ЕСМ & 262.625
\end{tabular}

Таблица 2. Таблица спектральных линий КР, характерных для образцов костных биоимплантатов $[12,17,18]$

\begin{tabular}{|c|c|}
\hline Рамановский сдвиг, $\mathrm{cm}^{-1}$ & Фрагмент, колебание \\
\hline $\begin{array}{c}814 \\
855,875 \\
894 \\
917 \\
937 \\
956 \\
974 \\
1001 \\
1026 \\
1048 \\
1068 \\
1084 \\
1100 \\
1167 \\
1198 \\
1230-1280 \\
1307 \\
1375 \\
1420 \\
1450 \\
1555-1585 \\
1603 \\
1627 \\
1655-1675 \\
1735\end{array}$ & 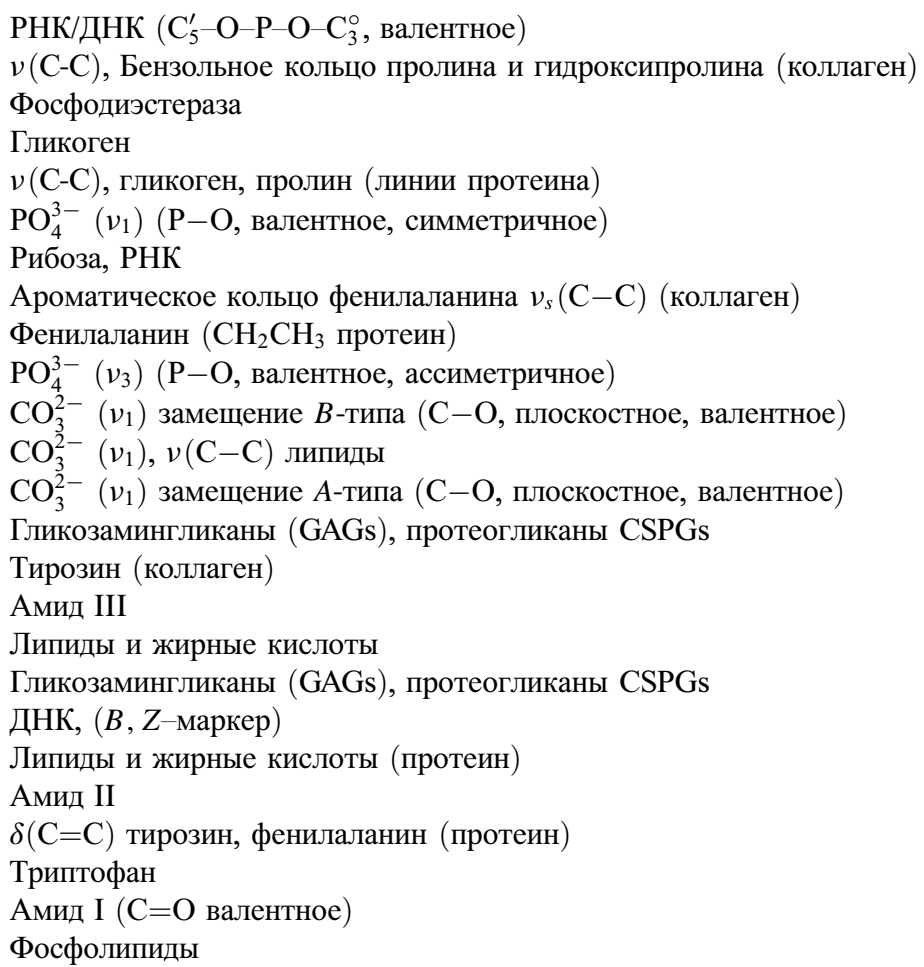 \\
\hline
\end{tabular}

\section{Применение метода главных компонент}

Метод РСА реализован в программной среде Тhe Unscrambler X.

На рис. 3 показано, что основные отличия между кадаверными и интраоперационными образцами описывает главная компонента РС-1, причем эти отличия являются самыми значительными. Положительные значения PC-1 в главной степени характерны для кадаверных образцов.

Из анализа зависимостей на рис. 3 и 4 и выходных данных РСА можно сделать следующие выводы. 


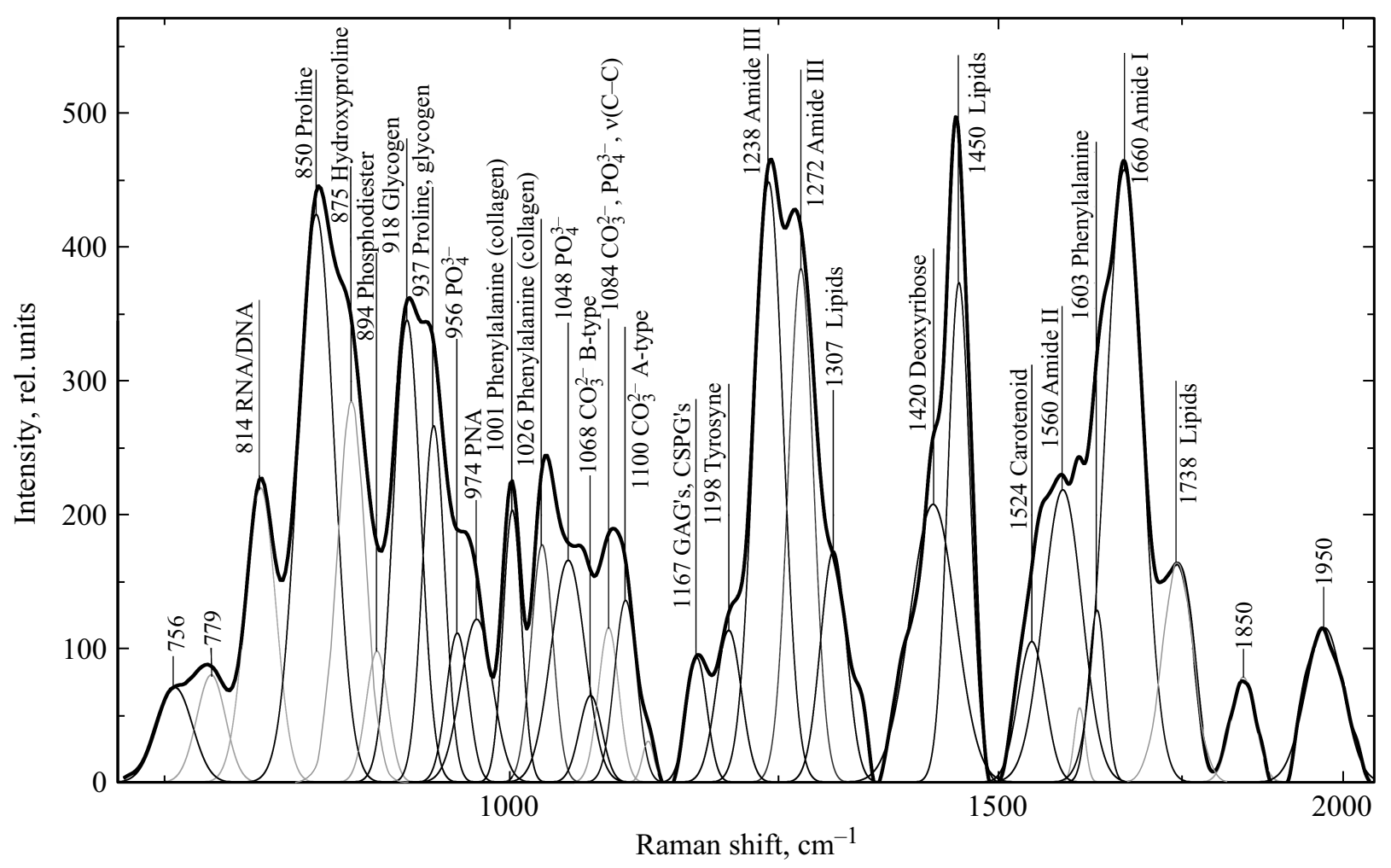

Рис. 2. Разложение спектрального контура деминерализованных образцов костной ткани.

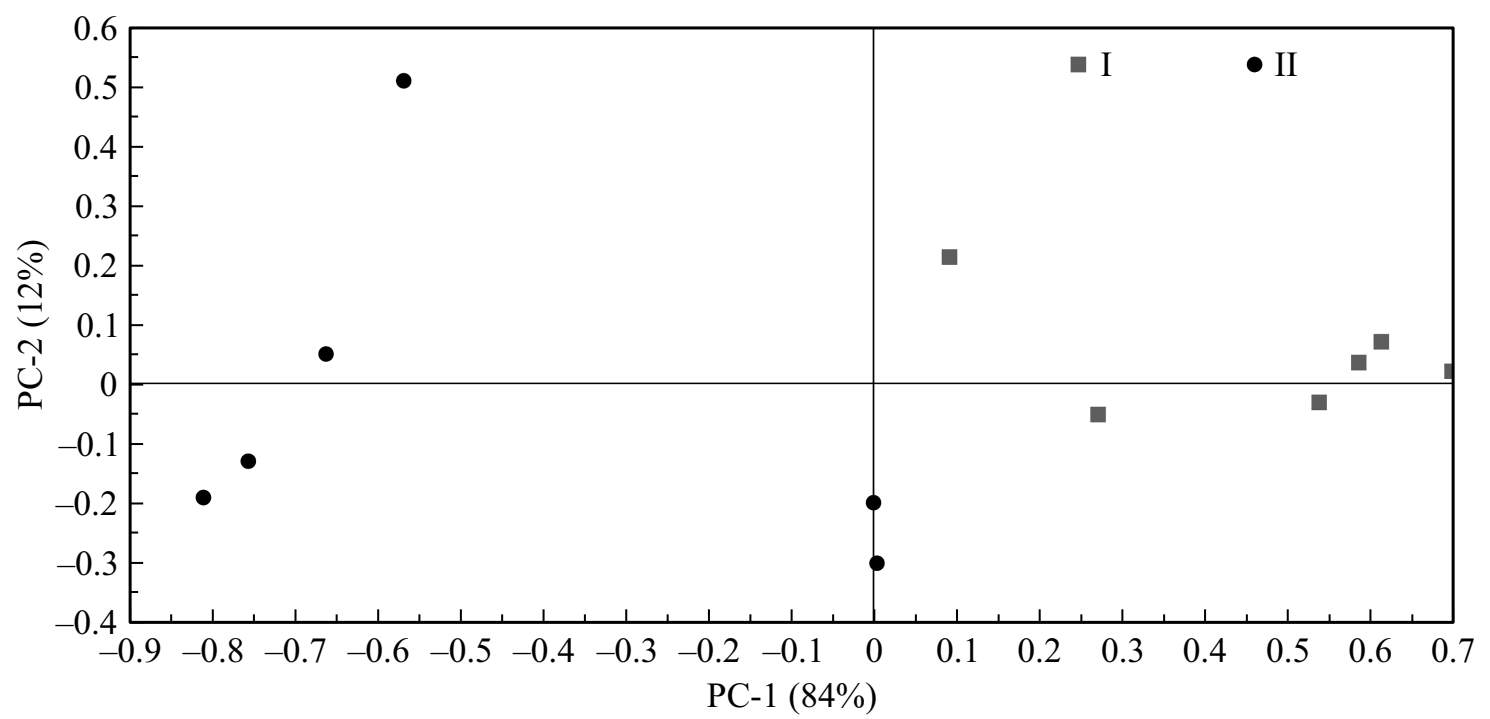

Рис. 3. График счетов спектров КР деминерализованных образцов костной ткани: I — кадаверная, II — интраоперационная.

1. РС-1 описывает различия между кадаверными и интраоперациоными образцами и характеризуется значениями двух групп коэффициентов: 1) $1560 \mathrm{~cm}^{-1}$ (амид II), 1450 (липиды и жирные кислоты), $1420 \mathrm{~cm}^{-1}$ (ДНК) и $1735 \mathrm{~cm}^{-1}$ (фосфолипиды); 2) $855 \mathrm{~cm}^{-1}$ (пролин), 917, $937 \mathrm{~cm}^{-1}$ (гликоген), 1001, $1026 \mathrm{~cm}^{-1}$ (фенилаланин); Переменные первой группы имеют значения выше в интраоперационных образцах, а для кадаверных ха- рактерны более высокие значения переменных второй группы.

2. При этом чем выше значение PC-1 для переменной, тем в большей степени она влияет на наблюдаемое различие в компонентном составе, что, например, видно из значения коэффициента $k_{1735}$. Интенсивность спектральной линии $1735 \mathrm{~cm}^{-1}$, соответствующей колебаниям фосфолипидов, выше для интраоперационных образцов. 


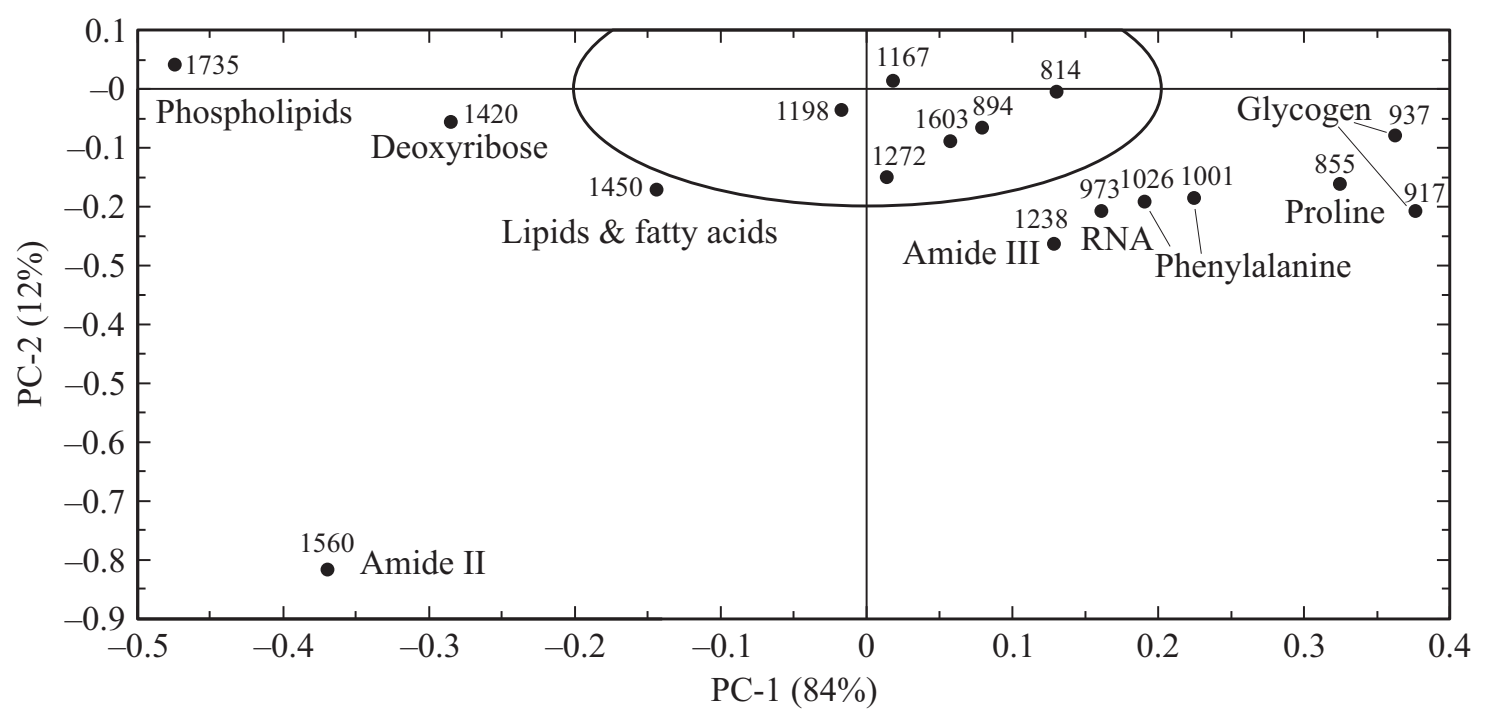

Рис. 4. График нагрузок спектральных линий спектров КР образцов деминерализованной костной ткани.
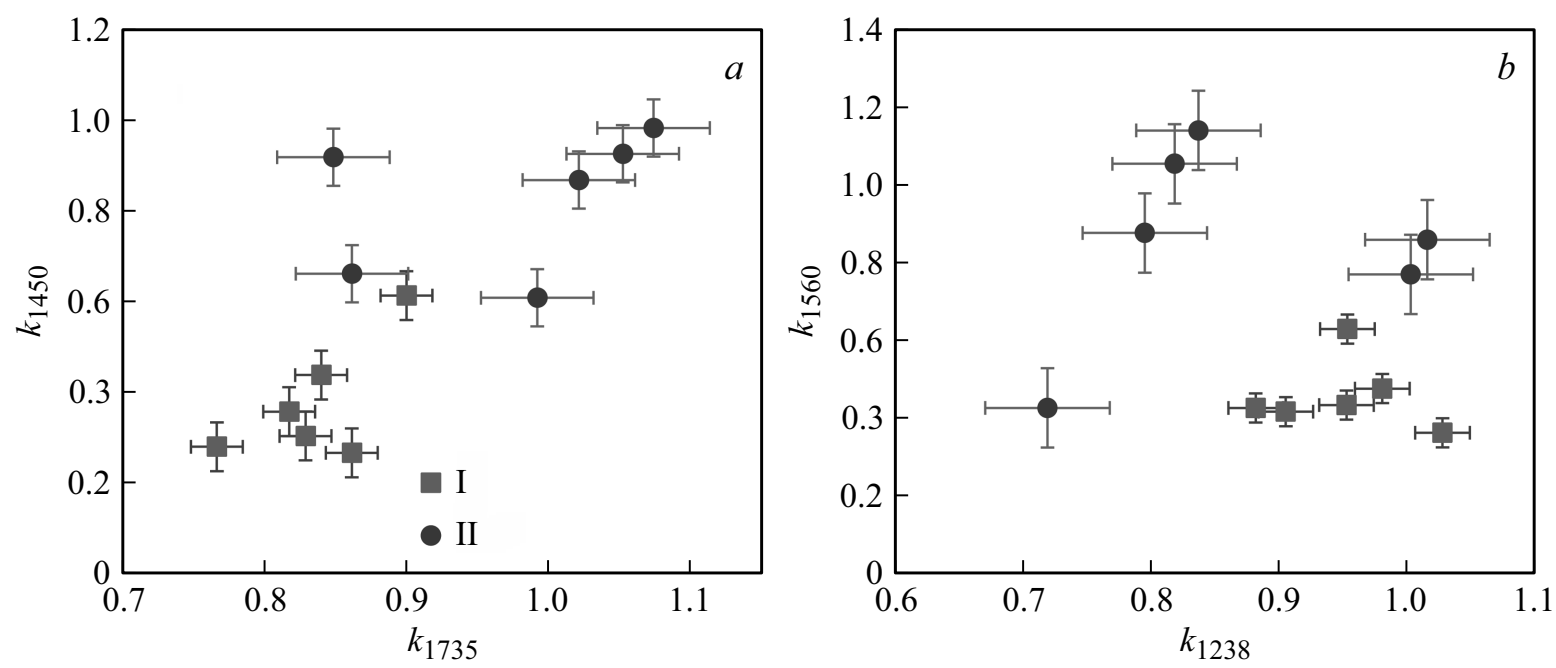

Рис. 5. Двумерные диаграммы введенных коэффициентов: I — кадаверная, II — интраоперационная.
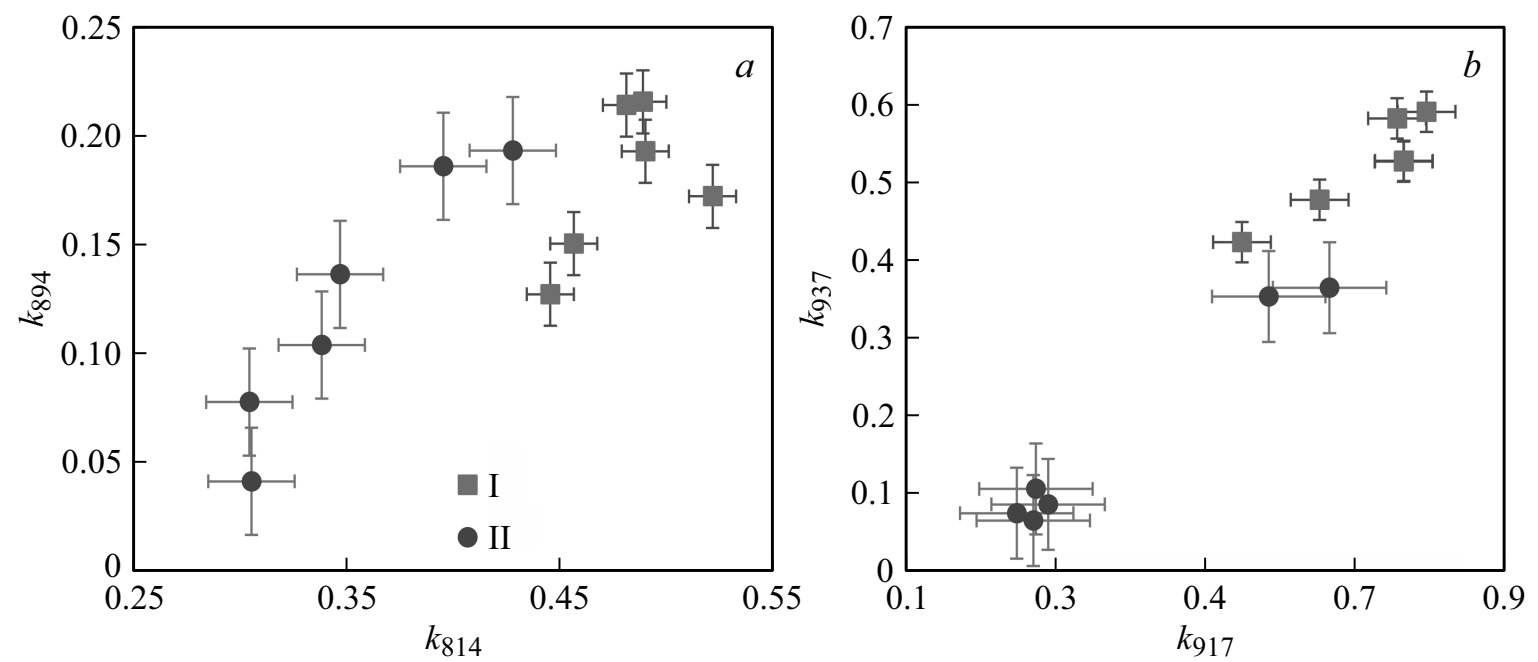

Рис. 6. Двумерные диаграммы введенных коэффициентов: I — кадаверная, II — интраоперационная. 
3. Из значений коэффициентов $k_{1167}, k_{1198}, k_{1603}$ видно, что относительная концентрация гликозамингликанов, протеогликанов и тирозина, входящих в экстраклеточный матрикс костной ткани, остается неизменной вне зависимости от источника получения материала, что указывает на сохранность компонентов, играющих важную роль в процессе приживляемости имплантата.

4. Значения коэффицента $k_{1001}$ отражают относительную концентрацию фенилаланина. С учетом данных на рис. 4 можно сказать, что имеются отличия между группами, т.е. источник получения биоматериала влияет на относительную концентрацию, причем для кадаверных материалов значения в среднем выше.

5. Исходя из этого видно, что имеются большие различия в компонентном составе в зависимости от источника получения деминерализованного костного биоимплантата.

\section{Двумерный анализ введенных коэффициентов}

Подробный анализ приведен на рис. 5,6, где представлены двумерные диаграммы введенных коэффициентов, на которых также видны различия и сходства между образцами двух групп.

Белок Long-chain-fatty-acid CoA ligase 1, расположенный в пероксиомах, отвечает за активацию длинноцепочечных жирных кислот как для синтеза клеточных липидов, так и для деградации путем бета-окисления. На рис. 5, $a$ представлены характерные области групп образцов и видно, что коэффициенты $k_{1735}, k_{1450}$, отражающие относительную концентрацию жирных кислот и липидов в составе коллагена, для интраоперационных образцов выше, чем для кадаверных.

Значения коэффициентов $k_{1238}$ и $k_{1560}$ (рис. 5,b) отражают соотношение интенсивностей линий амидов. С учетом данных рис. 1 видно, что интенсивность линии амида II в интраоперационной костной ткани выше, чем в кадаверной, а значения коэффициента $k_{1238}$ не сильно отличаются для этих двух групп материалов.

Коэффициенты $k_{814}$ и $k_{894}$, отражающие значения относительной концентрации фосфопротеинов в составе ДНК, выше для кадаверных образцов. Также эти линии показывают наличие белка Secreted phosphoprotein 24, координирующего ремоделирование кости и развитие скелетной системы.

Из рисунка $6, b$ видно, что амплитуды линии 917 и $937 \mathrm{~cm}^{-1}$, соответствующие колебаниям гликогена, в зависимости от источника получения материала остаются высокими для кадаверной костной ткани, что говорит о достаточном наличии гликогенов и, в частности, белка Alpha-2-HS-glycoprotein. Этот белок способствует эндоцитозу, обладает опсоническими свойствами и влияет на минеральную фазу кости.

\section{Заключение}

Основные линии органических компонентов деминерализованных имплантатов $1560 \mathrm{~cm}^{-1}$ (амид II), 1450 (липиды и жирные кислоты), $1420 \mathrm{~cm}^{-1}$ (ДНК) и $1735 \mathrm{~cm}^{-1}$ (фосфолипиды); $855 \mathrm{~cm}^{-1}$ (пролин), 917, $937 \mathrm{~cm}^{-1}$ (гликоген), 1001, $1026 \mathrm{~cm}^{-1}$ (фенилаланин).

При использовании расширенного спектрального анализа спектров КР и протеомной масс-спектрометрии имплантатов, изготовленных на основе костной ткани, показаны основные различия кадаверных и интраоперационных материалов (линии 1450, 1735, 917 и 937,814 и 894 и $\left.1238,1560 \mathrm{~cm}^{-1}\right)$, наличие в них компонентов экстраклеточного матрикса, влияющих на их качество и обеспечивающих возможность хорошего клинического эффекта: гликозаминогликанов, коллагенов, пролинов, гидроксипролинов и фенилаланинов и протеинов. Биохимический анализ исследуемых биоматериалов с помощью протеомного анализа показал, что для интраоперационных образцов характерна большая концентрация коллагенов, фибронектина и тенасцина, чем для кадаверных.

Установлено, что введенные коэффициенты $k_{i}$ позволяют оценивать органические компоненты биоимплантатов, полученные из разных донорских материалов.

Таким образом, оптический метод оценки костных биоимплантатов по спектральным отношениям $k_{i}$ может быть в дальнейшем использован для оптимизации процесса их производства и для выбора донорского материала на этапе изготовления биоимплантатов.

\section{Финансирование работы}

Исследования проводились при финансовой поддержке российского фонда фундаментальных исследований (РФФИ), проект 18-315-20017\18.

\section{Конфликт интересов}

Авторы заявляют, что у них нет конфликта интересов.

\section{Список литературы}

[1] Davis H.E. // Topics in Multifunctional Biomaterials and Devices. 2008. N 10. P. 1-26.

[2] Eppley B.L., Pietrzak W.S., Blanton M.W. // J. Craniofac. Surg. 2005. V. 16. N 6. P. 981-989.

[3] Esposito M., Hirsch J.M., Lekholm U., Thomsen P. // European J. Oral Sciences. 1998. V. 106. N 1. P. 527-551.

[4] Cleland T.P., Deepak V. // Analytical Biochemistry. 2015. V. 472. P. $62-66$.

[5] Chen H., Xu P.W., Broderick N. // Proc. SPIE Las Vegas: Society of Photo-optical Instrumentation Engineers (SPIE). 2016. V. 9802 . P. 98021 L. doi $10.1117 / 12.2218783$

[6] Chen J.L., Duan L., Zhu W. et al. // J. Transl. Med. 2014. V. 12. N 88. doi 10.1186/1479-5876-12-88 
[7] Timchenko E.V., Timchenko P.E., Lichtenberg A., Assmann A., Volova L.T., Pershutkina S.V. // J. Biomed. Opt. 2017. V. 22. N 9. P. 091511. doi 10.1117/1.JBO.22.9.091511

[8] Timchenko E.V., Timchenko P.E., Volova L.T., Dolgushkin D.A., Shalkovsky P.Y., Pershutkina S.V. // J. Phys.: Conference Series. 2016. V. 737. N 1. P. 012050. doi 10.1088/1742-6596/737/1/012050

[9] Koljenović S., Schut T.B., Vincent A., Kros J.M., Puppels G.J. // Anal Chem. 2005. V. 77. N 24. P. 7958-7965.

[10] Anderson T.A. // Anesthesiology. 2016. V. 125. N 4. P. 793-804.

[11] Timchenko P.E., Timchenko E.V., Pisareva E.V., Vlasov M.Yu., Volova L.T., Frolov O.O., Kalimullina A.R. // J. Optical Technology. 2018. V. 85. N 3. P. 130-135.

[12] Rygula A., Majzner K., Marzec K.M., Kaczor A., Pilarczyk M., Baranska M. // J. Raman Spectrosc. 2013. V. 44. N 8. P. $1061-1076$.

[13] Guo Yu. Raman Spectroscopy of Glasses with High and Broad Raman Gain in the Boson Peak Region. Electronic Theses and Dissertations. 2006. P. 996.

[14] Anderson J.D. // Stem Cells. 2016. V. 34. N 3. P. 601.

[15] Zhao J. // Appl. Spectrosc. 2007. V. 61. N 11. P. 1225-1232.

[16] Motulsky H.J., Christopoulos A. Fitting Models to Biological Data Using Linear and Nonlinear Regression. A Practical Guide to Curve Fitting. San Diego CA: GraphPad Software Inc, 2003.

[17] Mandair G.S., Morris M.D. // BoneKEy Reports. 2015. V. 4. P. 620.

[18] Binoy J., Abraham J.P., Joe I.H., Jayakumar V.S., Petit G.R., Nielsen O.F. // J. Raman Spectroscopy. 2004. N 35. P. 939-946. 